\title{
Editorial: Where should we go from here?
}

In 1998, an issue of $T A V B$ was partially dedicated to the current status and future directions of Skinner's analysis of verbal behavior. Among the prominent behavior analysts who commented in that issue were Hank Schlinger, Charles Catania, John Donahoe, Genea Hall, Terry Knapp, Sam Leigland, Ullin Place, Joe Spradlin, Mark Sundberg, Kurt Salzinger, Ken Hutchinson, Ernie and Julie Vargas, and finally Jack Michael, who served as the discussant for all papers. In that issue, some common recommendations for the future of Skinner's (1957) analysis were made. They included, among other things, an increase in the number of empirical studies on topics typically dealt with by traditional psychologists, the use of computer and neural network simulations, applications of Skinner's approach to developing technologies for second language acquisition and programmed instruction, as well as a synthesis of different specialty areas concerned with language, including stimulus equivalence and relational frame theory. Many of the authors suggested that the study of verbal behavior may require the development of innovative methodologies, and that the journal could serve as the primary vehicle to disseminate those (incidentally, for those readers attempting to start a research program in verbal behavior, these papers may be quite handy). Reflecting back on the journal over the past few years, the question remains: Did these suggestions come to fruition?

In an extensive analysis of the empirical contributions of verbal behavior conducted by Dixon, Small, and Rosales (2007), the authors concluded that the majority of research in verbal behavior has been conducted with individuals with disabilities. A recent review of the articles published in TAVB between 1999 and 2008 (MarconDawson, Vicars, \& Miguel, 2010) reached the same conclusion. Although the number of empirical studies in verbal behavior has increased, most of these aimed at testing specific procedures to teach verbal skills to individuals with language deficits. This is surely the product of a metacontingency affecting our whole field, and whose discussion is beyond the point of my editorial.

So, despite our progress, we still do not have a comprehensive and widely accepted approach to language development or acquisition. A few years ago, when enrolled in a linguistics class at Harvard (at William James Hall), I learned that Skinner's book served as the catalyst for the Cognitive Revolution. That was the only merit assigned to the book. So, I am not so sure that we have addressed the recommendations made in 1998 , or if we have, the results of our work may have not made the impact we would have wished. So what should we do? I wish I had the answer to this question, but one avenue is to move beyond the basic verbal operants into the study of more complex verbal relations, and use $T A V B$ as a vehicle for the publication of innovative methodologies, new conceptual analyses, and critical reviews that could establish new lines of inquiry. Now that other behavioral journals have been publishing verbal behavior research, $T A V B$ can be the testing ground for new and exciting ways to study "language and cognition." This is not a new recommendation and $T A V B$ has to a certain extent been serving this purpose.

"This journal $[T A V B]$ has proved a much needed outlet for a broader range of methodologies and issues than it could be explored in the more constrained pages of the Journal of the Experimental Analysis of Behavior and the Journal of Applied Behavior Analysis ... there is value in a platform for speakers where the audience is less inclined to methodological conformity" (Knapp, 1998, p. 122).

The current issue is a perfect example of what $T A V B$ is all about. The first article by Michael, Palmer, and Sundberg summarizes what I find to be the most important work by Skinner; his treatment of multiple control. This paper should be read by every student taking a class on conceptual issues in behavior analysis, and I hope will also 
stimulate exciting lines of research whose products should start appearing in future issues of $T A V B$. The remaining articles included in this issue address a wide range of topics such as verbal conditional discrimination, rule-governed behavior, multipleexemplar training, autoclitic frames, automatic reinforcement, naming, and observational learning. Although my verbal behavior may be slightly distorted, I think this is the best issue of $T A V B$ yet. It also happens to be my last issue as the editor. I have now completed the 3-year term of what I considered was the most important position I have ever held. Over the past three years, the number of submissions to TAVB has doubled, we have a completely new editorial board comprised of active verbal behavior researchers, and issues are now available online through PubMed Central. The next step is to turn the journal into a two-volume publication, but I will leave this task to the next editor.

I am grateful and honored by the opportunity to have served as the editor for this journal. Jack Michael, Mark Sundberg, and David Palmer were the ones who first appointed me for the position, and continued to support me along the way with both Anna Petursdottir and Matthew Normand as ex- traordinary associate editors and Danielle LaFrance playing the role of editorial assistant. I could not have done it without this wonderful team. Finally, I would like to dedicate this issue to my mentor and role model, Jack Michael, who has shaped me into a radical behaviorist and whose influence is present in everything I do.

- Caio Miguel Editor

\section{REFERENCES}

Dixon, M. R., Small, S. L., \& Rosales, R. (2007). Extended analysis of empirical citations with Skinner's Verbal Behavior: 1984-2004. The Behavior Analyst, 30, 197-209.

Knapp, T. J. (1998). Current status and future directions of operant research on verbal behavior: Baselines. The Analysis of Verbal Behavior, 15, 121-123.

Marcon-Dawson, A., Vicars, S. M., \& Miguel, C. F. (2009). Publication trends in The Analysis of Verbal Behavior: 1999-2008. The Analysis of Verbal Behavior, 25, 123-132.

Skinner, B. F. (1957). Verbal behavior. New York. Appleton-Century Crofts. 